\title{
Modeling Long Memory In The Russian Stock Market: Evidence From Major Sectoral Indices
}

Kashif Saleem, Lappeenranta University of Technology, Finland

\begin{abstract}
This paper studies the market efficiency of modern Russian stock market. In particular, we look at the long memory in stock market volatility in the Russian financial market. To examine the temporal dependencies in depth we utilize major sectors of the Russian stock market. We take a GARCH modeling approach. Specifically, we estimate a FIGARCH model proposed by Baillie et al. (1996) using daily returns. We find evidence of long memory in all sectors of the Russian equity market, implying that, all the market sectors under investigation are weak form inefficient. Our results show that the volatility has a predictable structure in all the sectors of modern Russian stock market, signifying the need of regulatory and economic reforms within the Russian financial system.
\end{abstract}

Keywords: Russian Market Efficiency; FIGARCH; Temporal Dependencies; Russian Equity Market; Long Memory

\section{INTRODUCTION}

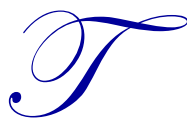

he purpose of this study is to re-examine the market efficiency of the modern Russian stock market. Specifically, we look at the long memory in stock market volatility in the Russian financial market. To inspect the temporal dependencies in depth we utilize major sectors of the Russian stock market. Particularly, we investigate the oil and gas, manufacturing, consumer goods, metals \& mining, telecom, power, and financial sectors of the Russian stock market. To study the stock market long memory we estimate FIGARCH model proposed by Baillie et al. (1996) using daily returns calculated by Moscow Interbank Currency Exchange (MICEX).

On the subject of the presence of apparent temporal dependencies in financial market volatility there exist mixed results in the existing literature. For instance, Green and Fielitz (1977), Peters (1996), Barkoulas et al. (2000), Cajueiro and Tabak (2004), Panas (2001), Tolvi (2003), Nawrocki (1995), Nath (2001), and Huang and Yang (1999) are among those who came to the conclusion that capital markets are characterized by long memory processes. Whereas, a large number of papers do not find any significant and robust evidence of positive long-term persistence in the financial markets (see, e.g., Aydogan \& Booth, 1988; Lobato \& Savin, 1998; Hiemstra \& Jones, 1997; Lux, 1996; Chow et al., 1996; Grau-Carles, 2005). At the same time, some researchers found temporary or little evidence of long-term memory in different stock markets (see, e.g., Lo, 1991; Willinger et al., 1999; Barkoulas \& Baum, 1996; Cajueiro \& Tabak, 2005; Sadique \& Silvapulle, 2001; Henry, 2002; Mills, 1993; Cavalcante \& Assaf, 2004; Zhuang et al., 2000).

To study the temporal dependencies in financial market volatility, researchers have applied different methodologies such as, classical rescaled-range (R/S) analysis (see, e.g., Hurst, 1951; Mandelbrot, 1972), modified rescaled-range (R/S) analysis introduced by Lo (1991), the spectral regression method suggested by Geweke and Porter-Hudak (1983) and different GARCH specifications. However, a very careful literature review shows that FIGARCH models outperform many of the other conditional heteroscedastic models in predicting and modeling different classes of assets, such as stock returns (see, e.g., Bollerslev \& Mikkelsen, 1996; Beine et al., 2002; Banerjee \& Sarkar, 2006), exchange rate returns (see, e.g., Baillie et al., 1996; Antonakakis \& Darby, 2013; Vilasuso, 2002), and futures returns (see, e.g., Baillie et al., 2007; Jin \& Frechette, 2004 in different market settings. 
Following the prior literature, we estimate a FIGARCH model to investigate the long-range dependence of different sectors of the Russian equity market. Most of the above mentioned studies focusing on the stock returns long-term memory belongs to the developed markets. There exist some papers who explore this phenomenon in emerging markets of different regions as well, though the work is still very scarce. Surprisingly, the Russian financial market could not attract the attention of financial researchers despite its diverse nature and potential for future investors as it should. Also, as per the author's knowledge, the framework adopted in this study has rarely been utilized in the case of the Russian market and particularly in a sectoral setting, or at least as used in this study.

We find evidence of long memory in the volatility of all the sectors of the Russian equity market, implying that, all the market sectors under investigation are weak form inefficient. Our results show that the volatility has a predictable structure in all the sectors of the modern Russian stock market, indicating the need of regulatory and economic reforms within the Russian financial system. It is our connotation that a better understanding of the nature of dependence (long memory processes), within the Russian market, is inevitable for international investors, multinational corporations, and portfolio managers, who all are involved in minimizing and managing their financial risk exposure and are in search of portfolio diversification opportunities.

The plan of the paper is as follows. The next section describes the FIGARCH model used to study longrange dependence in stock market returns. Section 3 presents the data in this study. Section 4 shows the empirical results. Section 5 concludes.

\section{MODEL SPECIFICATIONS}

The Autogressive Conditional Heteroscedasticity (ARCH) process proposed by Engle (1982) and generalized ARCH (GARCH) by Bollerslev (1986) are well known for volatility modeling and forecasting of stock returns. More precisely, ARCH family models capture the most prominent features of the time series data (also called stylized facts), such as volatility clustering, excess kurtosis, and fat-tailedness. However, to explain how persistent volatility is, the GARCH process can easily be extended to identify the long memory process, a common observation in actual data, through a fractionally integrated procedure proposed by Baillie et al. (1996), specifically, the Fractionally Integrated Generalized Autoregressive Conditional Heteroscedastic (FIGARCH) process.

We start our empirical specification with the GARCH (p, q) process introduced by Bollerslev (1986), we can write the conditional variance as:

$$
h_{t}=w+\sum_{i=1}^{q} \alpha_{i} \varepsilon_{t-i}^{2}+\sum_{i=1}^{p} \beta_{i} h_{t-i}
$$

The primary constraint of this model is that all the expounding variables must be positive i.e., ${ }^{w}, \alpha, \beta \geq 0$, this is known as the non-negativity restriction. Further, for stationarity we require that $\alpha+\beta$ is less than unity. However, if this restriction violates, i.e., $\alpha+\beta \geq 1$ we conclude that the shocks are persistent. Hence, to account for the persistency of shocks an IGARCH $(1,1)$ model proposed by Engle and Bollerslev (1986) can be written as:

$$
h_{t}=w+\sum_{i=1}^{q}\left(1-\beta_{i}\right) \varepsilon_{t-i}^{2}+\sum_{i=1}^{p} \beta_{i} h_{t-i}
$$

where $0 \triangleleft \beta_{i} \triangleleft 1$

The IGARCH model implies infinite persistence of the conditional variance to a shock in squared returns. The IGARCH process can also be illustrated as an ARMA (m, p) process:

$$
\phi(L)(1-L) \varepsilon_{t}^{2}=w+[1-\beta(L)] v_{t}
$$


The fractionally integrated GARCH or FIGARCH class of models is obtained by replacing the first difference operator $(1-L)$ in the above model with the fractional differencing operator $(1-L)^{d}$ where $d$ is a fraction $0<\mathrm{d}<1$. Thus, the FIGARCH class of models can be obtained by considering:

$$
\phi(L)(1-L)^{d} \varepsilon_{t}^{2}=w+[1-\beta(L)] v_{t}
$$

The FIGARCH process identifies potential presence of long memory or the subsistence of dependencies in financial time series mainly due to the hyperbolically decaying autocorrelation function, or in other words, long memory process can be illustrated through a fractionally integrated procedure. This means, the level of integration is less than one, however superior to zero, implying that the impacts of a shock continue over an extensive period of time. The main advantage of the FIGARCH process is that it allows for long memory in the conditional variance which is characterized by the fractional integration parameter $\boldsymbol{d}$ and the short-term dynamics can be modeled through the traditional GARCH parameters. Following Baillie et al. (1996) we adopt the Quasi maximum likelihood estimation (QMLE) technique.

\section{DATA AND DESCRIPTIVE STATISTICS}

The data comprise daily price indices calculated by Moscow Interbank Currency Exchange (MICEX) for the Russian equity market: oil and gas, manufacturing, consumer goods, metals \& mining, telecom, power, and financial sectors. The dataset starts from December 2004 and ends at September 2013, yielding 2164 daily observations in total for each series. The beginning of our data set is due to the availability of MICEX sectoral indices. Figure 1 shows the development of different sectors of the Russian stock market. All the data are retrieved from the official website of MICEX and daily returns are constructed as the first difference of logarithmic prices multiplied by 100 .

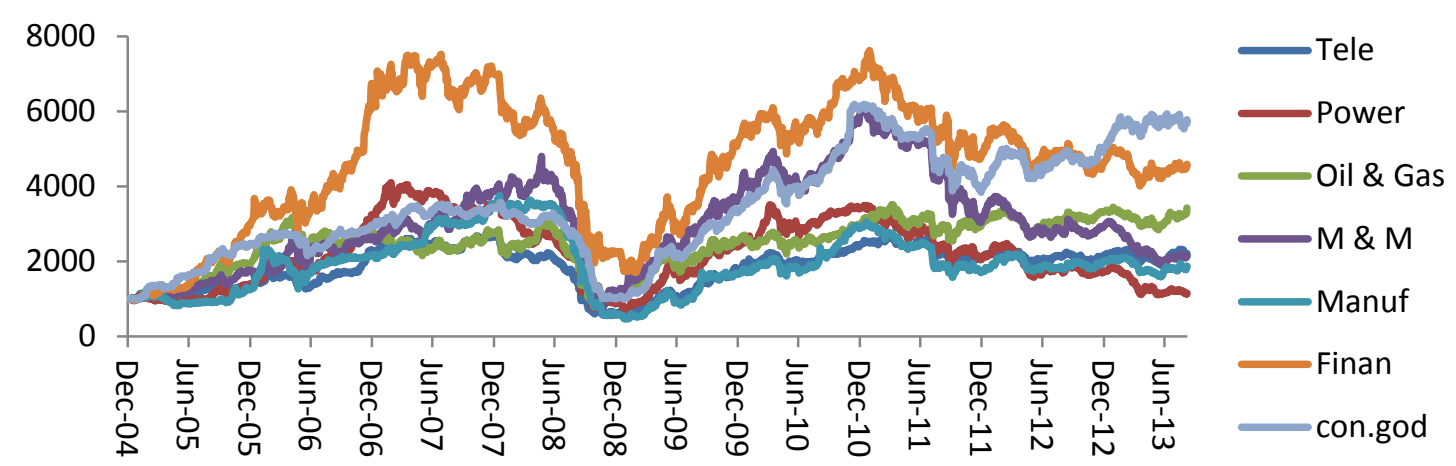

Figure 1: Development of Different Sectors of the Russian Equity Market from Dec. 2004 - Sep. 2013

Before formal investigation of long memory in the Russian equity market, we inspect the time-series properties of our data set using primary techniques, for instance, stationarity in the time series is checked by applying the Augmented Dickey Fuller (ADF) test. To check the null hypothesis of normal distribution, we calculate the Jarque-Bera test statistic. Finally, to investigate the null that autocorrelation coefficients up to 20 lags are zero, we compute Ljung and Box (1978) test statistic, together with the ARCH LM-statistic (five lags) on each return series. The results shown in Table 1, in general, support the findings of prior studies and allow us to reject the null hypothesis that returns have unit root in favor of alternate hypothesis of stationarity; P-values are reported in the table (even at $1 \%$ MacKinnon critical value). The Jarque-Bera normality and Engle's Lagrange Multiplier ARCH tests both reveal that equity return data of all the sectors of MICEX exhibit non-normality and ARCH effects; Pvalues are reported in the table. These primary findings grant confirmation against the market efficiency hypothesis and allow us to use GARCH specification through LB statistics and ARCH LM-statistic. 
Table 1: Descriptive Statistics of the Russian Stock Market for the Daily Return Indices: Dec. 2004 - Sep. 2013

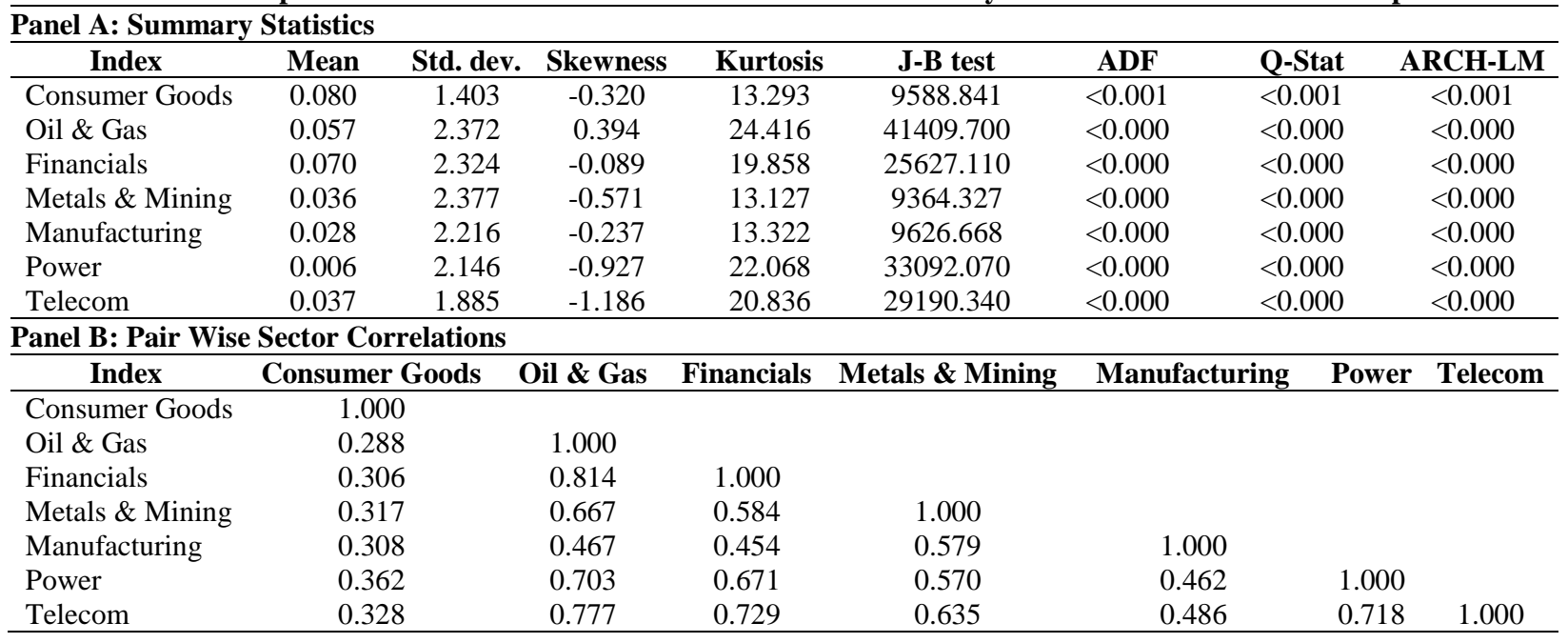

\section{EMPIRICAL RESULTS}

Using the MICEX calculated daily stock return data, we re-examine the subject of whether or not actual stock market prices reveal temporal dependence. We utilize major sectors of the Russian stock market. Mainly, we investigate the oil and gas, manufacturing, consumer goods, metals \& mining, telecom, power and financial sectors of the Russian stock market. Our empirical investigation is based on the GARCH family models. First, to model the volatility dynamics of different sectors of the modern Russian equity market, we utilize the traditional GARCH (1, 1) model. Second, to check the volatility persistence, we adopt IGARCH $(1,1)$ technique. Finally, to investigate the long run dependence in stock returns of different sectors of MICEX, we employ FIGARCH $(1,1)$ framework. The results of estimated GARCH, IGARCH and FIGARCH models are reported in Table 2.

Panel A of Table 2 presents GARCH $(1,1)$ estimations of all the sectors under investigation. The results show that both the ARCH and GARCH parameters $(\alpha$ and $\beta)$ are statistically significant for all the indices under investigation, which confirm the existence of the time-varying conditional variance. It is also evident from Panel A of Table 2 that the parameters of the conditional variance equations are all positive and meet the positivity constraint for the GARCH $(1,1)$ specification. However, the sum of $\alpha$ and $\beta$ parameters is very close to the unity, indicating the persistence of the volatility in all the indices. One shortcoming of the traditional GARCH model is its failure to capture long-range dependence or to account for persistence of volatility in the data. Hence, we utilize the IGARCH process proposed by Engle and Bollerslev (1986). The IGARCH model implies infinite persistence of the conditional variance to a shock in squared returns. Panel B of Table 2 presents IGARCH $(1,1)$ estimations of all the sectors under investigation. The results are very similar to the standard GARCH $(1,1)$ estimations presented in Panel A, confirming the temporal dependencies in all the sectors of Russian equity market.

Finally, FIGARCH $(1,1)$ model is employed in order to investigate the existence of possible temporal dependencies in the volatility of all the sectors of the Russian equity market under investigation. The FIGARCH process identifies potential presence of long memory or the subsistence of dependencies in financial time series mainly due to the hyperbolically decaying autocorrelation function. Results from this model are shown in Panel C of Table 2. As per our results, the fractional differencing parameter, $d$, is found to be significantly different from zero and is within the theoretical value (i.e., $0<d<1$ ). This indicates that the volatility of all the sectors of the Russian equity market under investigation clearly exhibits a long memory process. It is our connotation that our findings show the importance of modeling long memory in volatility and suggests that future volatility depends on its past realizations and, as a result, is predictable. Our findings also support the findings of prior studies on both emerging and developed markets.

To conclude, we report the sample skewness and kurtosis for the standardized residuals, (denoted by b3 and b4 in Table 2), also Ljung-Box portmanteau tests for up to 20th-order serial correlation in the standardized and the 
squared standardized residuals (denoted by $\mathrm{Q}_{20}$ and $\mathrm{Q}_{20}^{2}$ in table 2 ) as diagnostic tests for all three models. While comparing different GARCH family models based on diagnostic tests, we found FIGARCH model performs better than the other two models, which is again consistence with the most recent prior research on the topic.

Table 2: Long Memory in the Russian Stock Market Volatility, Estimated From A Uni-Variate GARCH $(1,1)$, IGARCH $(1,1)$ and FIGARCH $(1,1)$ Model of Daily Return Indices from Dec. 2004 - Sep. 2013.

\begin{tabular}{|c|c|c|c|c|c|c|c|}
\hline \multicolumn{8}{|c|}{ Panel A: GARCH(1. 1) Estimations } \\
\hline Parameters & Consumer Goods & Oil \& Gas & Financials & Metals \& Mining & Power & Telecom & Manufacturing \\
\hline$\mu$ & 0.0337 & $0.077^{*}$ & $0.070 *$ & 0.303 & -0.006 & $0.044 *$ & 0.027 \\
\hline$\omega$ & $0.052 *$ & $0.049 *$ & $0.042 *$ & $0.055^{*}$ & 0.023 & $0.056^{*}$ & $0.062 *$ \\
\hline$\alpha$ & $0.212 *$ & $0.091 *$ & $0.091 *$ & $0.080 *$ & $0.141 *$ & $0.138 *$ & $0.166^{*}$ \\
\hline$\beta$ & $0.799 *$ & $0.892 *$ & $0.899 *$ & $0.904 *$ & $0.870^{*}$ & $0.838 *$ & $0.833^{*}$ \\
\hline$b_{3}$ & $1.647 *$ & $-0.311 *$ & $0.087 *$ & $-0.439 *$ & $-0.241 *$ & $-0.273 *$ & $-0.087 *$ \\
\hline$b_{4}$ & $28.732 *$ & $6.849^{*}$ & $5.466 *$ & $5.414 *$ & $4.644 *$ & $5.037 *$ & $7.578 *$ \\
\hline$Q_{(20)}$ & $69.53 *$ & 9.610 & 26.391 & 25.920 & $78.474 *$ & $39.007 *$ & $56.996 *$ \\
\hline$Q_{(20)}^{2}$ & 3.859 & 8.454 & 21.938 & 8.415 & 14.393 & 11.155 & 17.144 \\
\hline \multicolumn{8}{|c|}{ Panel B: IGARCH(1. 1) Estimations } \\
\hline Parameters & Consumer Goods & Oil \& Gas & Financials & Metals \& Mining & Power & Telecom & Manufacturing \\
\hline$\mu$ & 0.035 & $0.079 *$ & $0.071^{*}$ & 0.027 & -0.006 & $0.042 *$ & 0.027 \\
\hline$\omega$ & $0.055^{*}$ & $0.034 *$ & $0.035^{*}$ & $0.042 *$ & $0.028 *$ & $0.051 *$ & $0.062 *$ \\
\hline$\beta$ & $0.799 *$ & $0.903 *$ & $0.901 *$ & $0.905^{*}$ & $0.869 *$ & $0.833^{*}$ & $0.834 *$ \\
\hline$d$ & 1.000 & 1.000 & 1.000 & 1.000 & 1.000 & 1.000 & 1.000 \\
\hline$b_{3}$ & $1.616^{*}$ & $-0.298 *$ & $0.113 *$ & $-0.457 *$ & $-0.252 *$ & $-0.234 *$ & $-0.088^{*}$ \\
\hline$b_{4}$ & $28.585^{*}$ & $7.917 *$ & $5.602 *$ & $5.834 *$ & $4.656^{*}$ & $5.315^{*}$ & $7.578^{*}$ \\
\hline$Q_{(20)}$ & $70.712 *$ & 10.198 & 27.575 & 25.597 & $78.758 *$ & $37.404 *$ & $56.993 *$ \\
\hline$Q_{(20)}^{2}$ & 3.765 & 6.601 & 19.087 & 9.093 & 12.991 & 12.797 & 17.144 \\
\hline \multicolumn{8}{|c|}{ Panel C: FIGARCH(1. 1) Estimations } \\
\hline Parameters & Consumer Goods & Oil \& Gas & Financials & Metals \& Mining & Power & Telecom & Manufacturing \\
\hline$\mu$ & $0.048^{*}$ & $0.079 *$ & $0.066^{*}$ & 0.029 & -0.006 & $0.041 *$ & 0.025 \\
\hline$\omega$ & $0.095^{*}$ & 0.056 & -0.036 & $0.074 *$ & 0.022 & $0.085^{*}$ & $0.109 *$ \\
\hline$\beta$ & 0.099 & $0.515^{*}$ & $0.363 *$ & $0.829 *$ & $0.409^{*}$ & $0.370 *$ & $0.372 *$ \\
\hline$d$ & $0.391 *$ & $0.558 *$ & $0.450 *$ & $0.884 *$ & $0.560 *$ & $0.534 *$ & $0.579 *$ \\
\hline$b_{3}$ & $1.693 *$ & $-0.223 *$ & $0.085^{*}$ & $-0.448 *$ & $-0.237 *$ & $-0.289 *$ & $-0.151 *$ \\
\hline$b_{4}$ & $32.647 *$ & $6.951 *$ & $5.149 *$ & $5.741 *$ & $4.789 *$ & $4.925^{*}$ & $7.485^{*}$ \\
\hline$Q_{(20)}$ & $82.106^{*}$ & 10.436 & $28.594 *$ & $28.671 *$ & $79.900 *$ & $38.693 *$ & $59.855^{*}$ \\
\hline$Q_{(20)}^{2}$ & 1.927 & 6.644 & $31.254 *$ & 8.097 & 9.824 & 14.401 & 17.820 \\
\hline
\end{tabular}

In summary, we provide evidence of long memory in the volatility of all the sectors of the Russian equity market, which suggest that, all the market sectors under examination are weak form inefficient. This is an evidence of violation of efficient market hypothesis, which can lead to the arbitrage opportunities for international investors who are interested to invest in one of the fastest growing financial markets - the Russian equity market. Furthermore, our results confirm that the volatility has a predictable structure in all the sectors of the modern Russian stock market, indicating the need of regulatory and economic reforms within the Russian financial system.

\section{CONCLUSIONS}

In this study we attempt to re-examine the market efficiency of the modern Russian stock market. Specifically, we look at the long memory in stock market volatility in the Russian financial market. To inspect the temporal dependencies in depth we utilize major sectors of the Russian stock market. To study the stock market long memory we estimate FIGARCH model proposed by Baillie et al. (1996) using daily returns calculated by Moscow Interbank Currency Exchange (MICEX). We find evidence of long memory in the volatility in all the sectors of the Russian equity market. This implies that all the market sectors under investigation are weak form inefficient. Our results show that the volatility in different sectors of modern Russian stock market has a predictable structure. Our results indicate the need of regulatory and economic reforms within the Russian financial system. As per our empirical investigation, FIGARCH model performs better than the tradition GARCH models. 


\section{AUTHOR INFORMATION}

Kashif Saleem, Ph.D., Lappeenranta University of Technology, School Of Business, Mailing Address: P.O. Box 20, 53851 Lappeenranta, Finland. Tel. +358 5621 7284, Fax. +358 5621 7299. E-mail: Kashif.Saleem@Lut.Fi

\section{REFERENCES}

1. Aydogan, K., \& Booth, G. G. (1988). Are there long cycles in common stock returns? Southern Economic Journal, 55, 141-149.

2. Antonakakis, N., \& Darby, J. (2013). Forecasting volatility in developing countries' nominal exchange returns. Applied Financial Economics, 23, 1675-1691.

3. Bollerslev, T. (1986). Generalized autoregressive conditional heteroskedasticity. Journal of Econometrics, 31, 307-327.

4. Baillie, R. T., Bollerslev, T., \& Mikkelsen, H. O. (1996). Fractionally integrated generalized autoregressive conditional heteroskedasticity. Journal of Econometrics, 74, 3-30.

5. Barkoulas, J. T., Baum C. F., \& Travlos, N. (2000). Long memory in the Greek stock market. Applied Financial Economics, 10, 177-184.

6. Barkoulas, J. T., \& Baum, C. F. (1996). Long term dependence in stock returns. Economics Letters, 53, 253-259.

7. Bollerslev, T., \& Mikkelsen, H. O. (1996). Modeling and pricing long memory in stock market volatility. Journal of Econometrics, 73, 151-184.

8. Beine, M., Laurent, S., \& Lecourt, C. (2002). Accounting for conditional leptokurtosis and closing days effects in FIGARCH models of daily exchange rates. Applied Financial Economics, 12, 589-600.

9. Banerjee, A., \& Sarkar, S. (2006). Modeling daily volatility of the Indian stock market using intra-day data. (Working paper WPSNO.588). Calcutta: Indian Institute of Management.

10. Baillie, R. T., Han, Y. W., Myers, R. J., \& Song, J. (2007). Long memory models for daily and high frequency commodity futures returns. The Journal of Futures Markets, 27, 643-668.

11. Cajueiro, D. O., \& Tabak, B. M. (2004). Evidence of long range dependence in Asian equity markets: The role of liquidity and market. Physica A: Statistical Mechanics and its Applications, 342, 656-664.

12. Chow, K. V., Pan, M.-S., \& Sakano, R. (1996). On the long-term or short-term dependence in stock prices: Evidence from international stock markets. Review of Quantitative Finance and Accounting, 6, 181-194.

13. Cajueiro, D. O., \& Tabak, B. M. (2005). Possible causes of long-range dependence in the Brazilian stock market. Physica A: Statistical Mechanics and its Applications, 345, 635-645.

14. Cavalcante, J., \& Assaf, A. (2004). Long range dependence in the returns and volatility of the Brazilian stock market. European Review of Economics and Finance, 3, 5-22.

15. Engle, R. F. (1982). Autoregressive conditional heteroskedasticity with estimates of the variance of U.K. inflation. Econometrica, 50, 987-1008.

16. Engle, R. F., \& Bollerslev, T. (1986). Modelling the persistence of conditional variances. Econometric Reviews, 5, 1-500.

17. Greene, M. T., \& Fielitz, B. D. (1977). Long-term dependence in common stock returns. Journal of Financial Economics, 4, 339-349.

18. Grau-Carles, P. (2005). Tests of long memory: A bootstrap approach. Computational Economics, 25, 103113.

19. Geweke, J., \& Porter-Hudak, S. (1983). The estimation and application of long memory time series models. Journal of Time Series Analysis, 4, 221-238.

20. Huang, B. N., \& Yang, C. W. (1999). An examination of long-term memory using the intraday stock returns. (Technical Report 99-03). Clarion: Clarion University of Pennsylvania.

21. Hiemstra, C., \& Jones, J. D. (1997). Another look at long memory in common stock returns. Journal of Empirical Finance, 4, 373-401.

22. Henry, Ó. T. (2002). Long memory in stock returns: Some international evidence. Applied Financial Economics, 12, 725-729.

23. Hurst, H. E. (1951). Long-term storage capacity of reservoirs. Transactions of the American Society of Civil Engineers, 116, 770-799. 
24. Jin, H. J., \& Frechette, D. (2004). Fractional integration in agricultural futures price volatilities. American Journal of Agricultural Economics, 86, 432-443.

25. Lobato, I. N., \& Savin, N. E. (1998). Real and spurious long-memory properties of stock-market data. Journal of Business \& Economic Statistics, 16, 261-268.

26. Lux, T. (1996). Long-term stochastic dependence in financial prices: Evidence from the German stock market. Applied Economics Letters, 3, 701-706.

27. Lo, A.W. (1991). Long-term memory in stock market prices. Econometrica, 59, 1279-1313.

28. Ljung, G. M., \& Box, G. E. P. (1978). On a measure of lack of fit in time series models. Biometrika, 65, 297-303.

29. Mills, T. C. (1993). Is there long-term memory in UK stock returns? Applied Financial Economics, 3, 303306.

30. Mandelbrot, B. B. (1972). Statistical methodology for non-periodic cycles: From the covariance to R/S analysis. Annals of Economic and Social Measurement, 1, 259-290.

31. Nawrocki, D. (1995). R/S analysis and long term dependence in stock market indices. Managerial Finance, 21, 78-91.

32. Nath, G. C. (2001). Long memory and Indian stock market: Empirical evidence. UTIICM Conference Paper.

33. Peters, E. E. (1996). Chaos and order in the capital markets: A new view of cycles, prices, and market volatility. New York: John Wiley \& Sons. Inc.

34. Panas, E. (2001). Estimating fractal dimension using stable distributions and exploring long memory through ARFIMA models in Athens Stock Exchange. Applied Financial Economics, 11, 395-402.

35. Sadique, S., \& Silvapulle, P. (2001). Long-term memory in stock market returns: International evidence. International Journal of Finance \& Economics, 6, 59-67.

36. Tolvi, J. (2003). Long memory in a small stock market. Economics Bulletin, 7, 1-13.

37. Vilasuso, J. (2002). Forecasting exchange rate volatility. Economic Letters, 76, 59-64.

38. Willinger, W., Taqqu, M. S., \& Teverovsky, V. (1999). Stock market prices and long-range dependence. Finance and Stochastics, 3, 1-13.

39. Zhuang, Y., Green, C. J., \& Maggioni, P. (2000). The great rebound. The great crash and persistence in British stock prices. (Economic Research Paper No. 00/11). Loughborough University. 


\section{NOTES}

